\title{
Evidências empíricas da prática de Dumping no comércio internacional entre Brasil x China e Brasil x EUA
}

\author{
Elísio Ferreira Guedes de Sousa Neto ${ }^{1}$; Vera Lúcia do Nascimento ${ }^{2}$; Andressa Pacífico Franco Quevedo ${ }^{3}$
}

\begin{abstract}
Resumo: Atualmente as guerras cambiais e comerciais, tem se tornando palco de grandes e recorrentes discussões, é a partir disso que percebe-se uma busca desenfreada no sentindo de diminuir os possíveis impactos recorrentes a desvalorização da moeda para indústrias brasileiras. Por isso, o presente estudo busca entender como se dar o processo de casos de dumping em relações comerciais brasileiras e as medidas tomadas antidumping praticadas em território nacional, levando-se em consideração as relações brasileiras entre os Estados Unidos e China. Para obtenção dessas respostas, considera-se um levantamento de dados sobre casos de dumping que evidenciem relações bilaterais. Percebeu-se a presença de conflitos entre as nações estudadas, entretanto com variações de um país para outro, no entanto as respostas encontradas indicam que existem a presença de evidencias empíricas desse instrumento teórico.
\end{abstract}

PALAVRAS-CHAVE: Dumping, Brasil, Relações comerciais, ordem econômica

\section{Empirical evidence of Dumping practice in international trade between Brazil x China and Brazil x USA}

\begin{abstract}
Currently the exchange and trade wars, has become the scene of major and recurrent discussions, it is from this that we can see a frantic search in the feeling of reducing the possible recurring impacts the devaluation of the currency to Brazilian industries. Therefore, this study seeks to understand how to get the process of cases of dumping in Brazilian trade and anti-dumping measures taken practiced in the country, taking into account the Brazilian relations between the United States and China. To obtain these answers, it is considered a data collection on cases of dumping that show bilateral relations. It was noticed the presence of conflicts among the nations studied, though with variations from one country to another, however the solutions indicate that there is the presence of empirical evidence of this theoretical instrument.
\end{abstract}

KEYWORDS: Dumping, Brazil, trade relations, economic order

\section{Introdução}

As discussões sobre guerras cambiais e comerciais têm despertado grande interesse dos estudiosos já há algum tempo, em especial a partir da crise econômica de 2008 quando os países tomaram medidas protecionistas provocando uma guerra cambial.

\footnotetext{
${ }^{1}$ Bacharel em Ciências Econômicas pela Universidade Federal Rural de Pernambuco e-mail: elisio_ferreira@hotmail.com

${ }^{2}$ Bacharela em Ciências Econômicas pela Universidade Federal Rural de Pernambuco e-mail: veranascimentoo@ hotmail.com

${ }^{3}$ Mestre em Administração pela Universidade Federal de Pernambuco e-mail: andressadm@ gmail.com
} 
Id on Line Revista Multidisciplinar e de Psicoloqia

Id on Line Revista Multidisciplinar e de Psicologia

Neste sentido, a prática de dumping e políticas antidumping voltam com força para o centro das discussões acerca da política de comércio internacional brasileira como forma de mitigar os efeitos nocivos dessa desvalorização artificial da moeda para as indústrias brasileiras (Oliveira, 2011).

O estudo sobre dumping começa a ganhar destaque a partir da década de 70, apesar de esse instrumento já estar regulamentado desde o início do século XX, quando se percebe que países utilizam-se dessa tática desleal de comércio para minimizar seus problemas de competitividade dado um baixo nível de produtividade (ARAUJO JR., MACARIO e STEINFATT, 2001).

Sabe-se que os estudos sobre dumping têm sido realizados para as relações comerciais entre vários países, e esses estudos têm discutido sobre sua importância para entender distorções do comércio internacional. Dessa forma, este estudo busca entender os casos de dumping ocorridos nas relações comerciais brasileiras, bem como as medidas antidumping praticadas pelo Brasil e ainda os processos impetrados na Organização Mundial do Comércio OMC, focando as relações comerciais brasileiras com os Estados Unidos e a China. Para tanto será realizado um levantamento dos casos de dumping já estudados, de forma a evidenciar os casos que envolvem essas relações bilaterais (Brasil x China e Brasil x Estados Unidos).

Segundo Castilho (2006), o Brasil é o $6^{\circ}$ país mais citado em processos de dumping abertos pelos Estados Unidos. Já Barbosa e Mendes (2006) definem que as relações comerciais entre Brasil e China tendem a tornar-se uma parceria difícil e que a partir da adesão chinesa à Organização Mundial do Comércio, o Brasil deve adotar postura mais rigorosa no sentido de inibir a prática de dumping pela China.

A importância da temática fica evidente quando se analisa a literatura e percebe-se um grande movimento dos estudos sobre dumping, não mais se restringindo às análises em termos políticos da prática do dumping, mas tornando cada vez mais essa discussão em uma discussão teórica, a qual muda o foco para os efeitos das práticas de medidas antidumping sobre o comércio internacional (VASCONCELLOS e VASCONCELOS, 2005).

Tendo em vista os resultados encontrados por esses autores, este trabalho buscará ainda discutir os processos de comercialização entre os países citados, focando na análise das relações bilaterais de forma a evidenciar o uso da pratica do dumping, não só como medida defensiva, mas também como uma medida de política protecionista e desleal de comércio.

Vale ressaltar ainda, que este é um trabalho de grande importância, pois traz uma interligação entre a teoria econômica e as evidências empíricas que mostram a real aplicação de tais teorias. 
Id on Line Revista Multidisciplinar e de Psicoloqia

Id on Line Revista Multidisciplinar e de Psicologia

\section{Metodologia}

Em um primeiro momento procurou-se fontes que puderam aprofundar o conhecimento referente ao Dumping, levou-se em conta sua origem e suas principais características, em seguida utilizou-se ainda o método de abordagem hipotético-dedutivo, através de leitura e fichamento do material selecionado, com uma visão crítica para que assim pudessem explicar com precisão os resultados encontrados. Em um momento posterior, após a catalogação dos dados, estes foram explanados de forma particular, levando-se em conta os países analisados: Brasil, China e Estados Unidos. Os dados encontrados foram expostos em gráficos e tabelas, onde se pôde fazer uma análise comparativa para os anos em questão.

O detalhamento dos dados catalogados na página do Ministério do Desenvolvimento, Indústria e Comércio Exterior, foram extremamente importantes pois proporcionaram um estudo minucioso evitando possíveis erros.

\section{Dumping: Caracterização e Consequências}

Para avançar na discussão deve-se ter em mente alguns conceitos relativos à teoria sobre dumping, estes são de fundamental importância para o entendimento dos casos empíricos nas relações comerciais a serem estudadas. Dessa forma deve-se entender o conceito de Dumping.

Considera-se que há prática de dumping quando uma empresa exporta um produto a preço (preço de exportação) inferior àquele que pratica para o produto similar nas vendas para o seu mercado interno (valor normal). Desta forma, a diferenciação de preços já é por si só considerada como prática desleal de comércio (MDIC, 2009).

Este conceito também pode ser entendido como o caso em que o exportador faz uso extensivo da tarifa mantendo a Receita Marginal igual ao Custo Marginal para o mercado doméstico e com isso exportando a um preço menor FOB até igualar o custo marginal. Neste sentido, o dumping passa a ser uma estratégia de discriminação de preços entre dois mercados, o doméstico e o internacional (OLIVEIRA 2011).

Tratando ainda do conceito de dumping, há autores que defendem que deve ser considerado o custo de produção e não o preço no mercado doméstico, assim só se caracterizaria o dumping caso a empresa exportadora vendesse seu produto no mercado internacional com preço abaixo do custo de produção (VASCONCELOS e FIRME, 2011). 
Id on Line Revista Multidisciplinar e de Psicoloqia

Id on Line Revista Multidisciplinar e de Psicologia

Assim, de modo genérico, pode-se construir o conceito de dumping, levando-se em consideração as diferentes definições como sendo a venda do produto no mercado internacional a um preço inferior ao valor normal, onde podemos considerar o valor normal como sendo o preço praticado pelo exportador em seu mercado interno. Pode-se ainda dizer que tal prática pode passar a existir diante de algumas condições que distorcem as relações comerciais, que, por exemplo, podemos citar: segmentação dos mercados ou indústria imperfeitamente competitiva.

É importante ainda saber que além da definição tradicional de dumping, existem definições derivadas, como a de dumping inverso, quando a firma cobra preço de venda maior no mercado internacional, e ainda o dumping recíproco, que se refere ao caso em que há troca simultânea de um mesmo produto. Este último gera maior concorrência, porém, maiores custos de transporte (HIDALGO, 2013).

Como forma de evitar os efeitos do dumping sobre o mercado interno, os países aplicam medidas chamadas de antidumping. Essas medidas são normalmente usadas como forma de evitar distorções, porém muitos países buscam esse instrumento como forma ofensiva, na prática de protecionismo alfandegário, onde muitas vezes buscam-se desvios não intencionais no preço para tentar caracterizar o dumping e poder aplicar as penalidades legais.

No caso das medidas antidumping, estas são regulamentadas pela $\mathrm{OMC}$ e dão ao país prejudicado o direito de aplicar taxas inferiores ou equivalentes às margens de dumping aplicadas pelo parceiro comercial como forma de neutralizar os efeitos danosos da prática de dumping. Ainda se tratando dessas medidas, vale destacar que podem ser aplicadas de forma provisória quando se tratar de um dos seguintes casos:

- Quando houver uma determinação prévia da existência do dumping;

- Quando as autoridades competentes jugarem necessárias as medidas para evitar maiores danos;

- Quando houver decorrido pelo menos 60 dias da abertura da investigação, que deve estar em conformidade com as normas vigentes (MDIC, 2013).

Para entendermos melhor as relações e efeitos da política antidumping faz-se necessário, além de conhecer o conceito de dumping, entender um pouco sobre seu surgimento, objetivos, conflitos causados e relações entre os países envolvidos.

O dumping foi instituído em 1904 quando no Canadá foi criada a primeira lei antidumping. À época, o objetivo central dessa lei era proteger a economia de práticas abusivas de entrada em países estrangeiros pelos exportadores, todavia em tempos atuais, muito mais que uma política defensiva, o antidumping tem sido usado como uma política protecionista que visa a manutenção dos lucros e 
Id on Line Revista Multidisciplinar e de Psicoloqia

Id on Line Revista Multidisciplinar e de Psicologia

crescimento dos setores atingidos por preços menores, onde muitas vezes os países buscam encontrar propositalmente uma falha na exportação para que possam exercerem seus direitos (Castilho,2006).

"Os efeito de uma medida antidumping são bastante conhecidos. O efeito mais evidente é a redução das exportações de determinado país sobre as quais incide a medida antidumping. No entanto, Prusa (1997, 2001) e Bown e Crowley (2006) mostram que os efeitos antidumping são mais abrangentes, podendo afetar países não citados no processo" (Castilho; pag. 02, 2006).

Para que se entenda esse processo acima citado precisamos discutir os principais efeitos da política antidumping. Essa política, segundo Castilho, gera quatro principais efeitos: destruição de comércio "[onde] o direito antidumping nada mais é do que uma tarifa aduaneira e neste sentido ele deve reduzir os fluxos de importações do bem que faz face à proteção mais elevada" (CASTILHO; pag. 03, 2006); desvio de comércio onde a política antidumping eleva os preços dos bens comercializados por certo país, gerando um processo de substituição de importação por produtos de outros países que podem ter custos de produção mais elevados que o país em questão (CASTILHO, 2006); deflexão de comércio que [...] "ocorre quando um país, ao fazer face a medidas, redireciona suas exportações para terceiros mercados" (CASTILHO; pag. 03, 2006) em busca de diminuir as perdas decorrentes da restrição estabelecidas; e por fim depressão de comércio que é a imposição de medidas contra exportações nos mercados de destino de um determinado país, o que pode levar à redução das exportações para aquele mercado. Ex: três países $\mathrm{A}, \mathrm{B}$ e $\mathrm{C}, \mathrm{A}$ impõe restrições a $\mathrm{B}$ e $\mathrm{B}$ negocia com $\mathrm{C}$ sem contar com as negociações com B, C diminui suas negociações com $\mathrm{A}$ (CASTILHO, 2006).

\section{Relações Comerciais Brasil X China}

Desde o fim da década de 1970 com a abertura comercial chinesa iniciou-se um processo de expansão da China como grande comerciante internacional, onde foram feitas reformas que permitissem a este país alcançar vários mercados com mais competitividade. Para se ter noção da expansão da economia chinesa, o banco mundial divulga dados que mostram que a China cresceu em média $10 \%$ ao ano entre 1980 e 2010 e ainda expandiu a sua participação internacional de 1,5 para 8\% no mesmo período.

Em se tratando de comércio Brasil x China, este nos remete ainda a mais longe, e segundo Villela (2004), os primeiros contatos do governo brasileiro com o governo chinês ocorreram no final do século XIX. O comércio entre as duas nações, no entanto, teve dificuldades de se firmar, onde apenas a partir de 1974 com o reestabelecimento das relações diplomáticas passou a ter real 
Id on Line Revista Multidisciplinar e de Psicoloqia

Id on Line Revista Multidisciplinar e de Psicologia

importância e a evoluir. Todavia essa evolução foi de forma cautelosa até os anos 90, quando o Brasil passa por um processo de abertura comercial e a China por um aprofundamento das reformas econômicas, o que possibilitou uma melhora e um crescimento das relações.

Analisando a estrutura de comércio da China e comparando com os países da América-Latina, e mais especificamente com o Brasil, percebe-se uma maior evidência de complementariedade e menor grau de concorrência. É nesse contexto que a expansão econômica chinesa tem aumentado as exportações brasileiras, pois o Brasil é um país com grande disponibilidade de recursos e pode atender a demanda chinesas por produtos naturais.

Vale referir ainda, sobre o comércio entre esses dois países, que o aumento entre os anos de 2000 e 2007 cresceu quase onze vezes e que se percebe que os produtos manufaturados brasileiros têm tido relativamente pouco espaço na pauta chinesa. Em contra partida, os produtos chineses de caráter industrial têm aumentado cada vez mais na pauta de importação brasileira (PIRES, 2008). Para termos melhor noção da importância do comércio bilateral entre Brasil x China, vejamos um gráfico que mostra as relações da balança comercial brasileira para a relação com a China entre 1998 e 2004.

Gráfico 1- Exportações, Importações e Saldo Comercial do Brasil com a China, de 1998 a 2004 (em US\$ milhões).

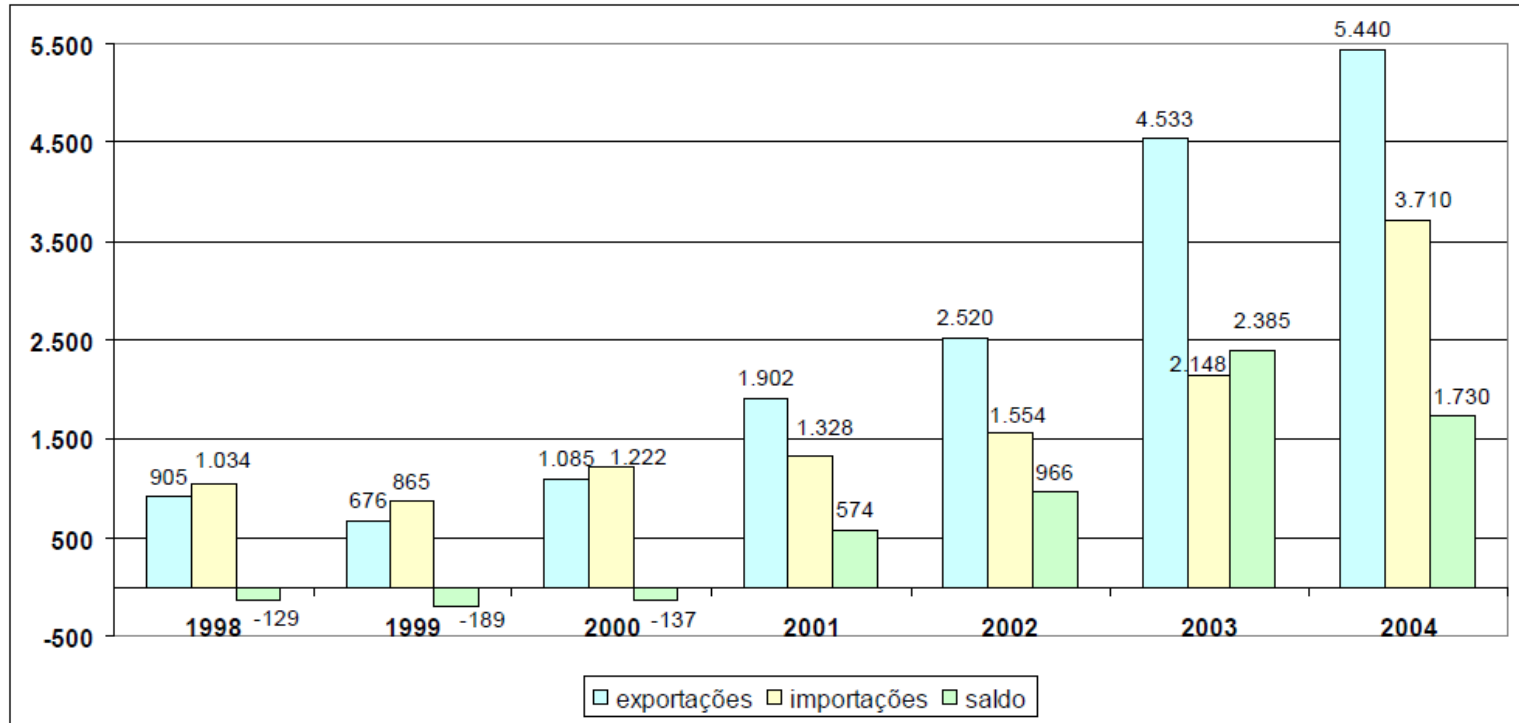

Pode-se notar com o Gráfico 1 que a partir do ano 2000 houve um aumento nas relações comerciais entre Brasil e China.

Todavia, as relações comerciais entre tais países não são compostas apenas por prosperidade econômica, existem vários conflitos nessas relações e dentre esses podemos analisar alguns casos de dumping e tentar identificar como tais casos influenciaram no comércio entre esses países. 
Id on Line Revista Multidisciplinar e de Psicoloqia

Id on Line Revista Multidisciplinar e de Psicologia

Atualmente, o Brasil tem 87 casos de dumping com medidas antidumping aplicadas e em vigor. Para se ter noção da importância da China nesse contexto, podemos destacar que só ela é responsável por 31 casos de dumping nessa relação comercial brasileira.

Sabemos que o livre comércio traz benefícios conhecidos para os países, como melhoria na renda e no dinamismo econômico. Neste contexto, a prática de dumping pela China e consequentemente a aplicação das medidas antidumping pelo Brasil trazem grande prejuízo ao comércio entre esses dois países.

Analisando o caso de ventiladores de mesas (Processo $\mathrm{n}^{\circ}$ 8414.51.10) do Brasil contra a China, temos uma aplicação de uma tarifa de 45,24\% sobre as importações desse item, em virtude de uma alteração no preço normal do produto, conforme consta no processo como sendo o motivo das medidas antidumping. Esse resultado nos mostra que o comércio bilateral entre os dois países passa longe do livre comércio e ainda mostra-se de relevante nível de protecionismo, podendo com isso ocorrer, neste caso dos ventiladores, o Desvio do Comércio, conforme proposto por Castilho e referenciado anteriormente, pois esses itens passam a ser menos competitivos no Brasil em relação a outros parceiros comerciais da China. Como consequência desse fato, também podemos ter preços no mercado doméstico brasileiro mais elevados devido a dois fatos: por possíveis Desvios do Comércio diminuindo a oferta ou por aumento de preços gerados pela aplicação da Tarifa de direito antidumping.

Outro caso importante a ser destacado é o de Ímãs Permanentes de Ferrite em Forma de Anel (processo $\mathrm{n}^{\circ}$ 8505.19.10), que são usados na indústria eletrônica como parte dos insumos. Este produto teve uma taxação de $43 \%$ como medida corretiva, ele foi considerado dumping por existir uma mudança artificial de nacionalidade para que fosse justificado o preço diferente do custo marginal. Tal fato faz com que o dinamismo industrial seja prejudicado e, de acordo com a teoria, causando uma Destruição do Comércio, pois segundo dados do processo, disponibilizados pelo MDIC, houve também um indeferimento das licenças de importação deste produto, fazendo com que a indústria brasileira não possa ter o acesso a este produto pelo preço comercializado originalmente, tornando assim o custo de produção significativamente superior ao planejado (MDIC).

Mostrando os casos de dumping acima discutidos, podemos perceber a aplicação empírica das teorias sobre dumping e medidas antidumping nas relações comerciais entre Brasil e China, evidenciando o efeito (através da Teoria) causado pela prática de medidas antidumping, que são necessárias para o combate a essa prática desleal de comércio. 
Id on Line Revista Multidisciplinar e de Psicoloqia

Id on Line Revista Multidisciplinar e de Psicologia

\section{Relações Comerciais Brasil X EUA}

O comércio bilateral entre Brasil e EUA apresentou na década de 90 uma forte expansão passando de cerca de U\$ 11 bilhões entre os anos de 89 e 91 para cerca de U\$\$ 26 bilhões entre os anos de 2000 e 2002 segundo dados da MDIC. Tais dados ainda mostram que as exportações brasileiras para os EUA ganharam força a partir do ano de 1999 quando até 2002 registrou um aumento de 57,6\%. Esses dados ainda evidenciam a importância dos EUA como parceiro comercial brasileiro.

No que se fere ao comércio entre Brasil e EUA, vale destacar que predominam os setores de bens manufaturados, onde as exportações brasileiras, entre 2000 e 2002, chegaram aos seguintes números: 22,6\% de equipamentos de transporte, 19,1\% máquinas e material elétrico representam e outros que podem ser observados na tabela 1 que segue.

Tabela 1 - Composição do comércio bilateral Brasil - EUA 2000/2002, em \%

\begin{tabular}{|c|c|c|c|c|c|}
\hline \multirow[b]{2}{*}{ seção } & \multirow[b]{2}{*}{ Descrição } & \multicolumn{2}{|c|}{ Importações Brasil-EUA } & \multicolumn{2}{|c|}{ Exportações Brasil-EUA } \\
\hline & & composição & $\begin{array}{c}\text { peso nas } \\
\text { import. totais }\end{array}$ & composição & $\begin{array}{c}\text { peso nas } \\
\text { import. totais }\end{array}$ \\
\hline I & Produtos animais & 0,3 & 4,7 & 1,2 & 6,2 \\
\hline II & Produtos vegetais & 0,7 & 4,3 & 2,6 & 7,7 \\
\hline III & Gorduras, óleos & 0,0 & 2,2 & 0,1 & 2,5 \\
\hline IV & Alimentos, bebidas, fumo & 0,6 & 10,5 & 4,3 & 8,4 \\
\hline $\mathrm{V}$ & Produtos minerais & 3,3 & 4,9 & 7,0 & 18,2 \\
\hline $\mathrm{Vl}$ & Produtos químicos & 19,4 & 27,1 & 3,8 & 18,0 \\
\hline VII & Plásticos e borrachas & 6,9 & 29,8 & 2,0 & 17,8 \\
\hline VIII & Couros e peles; artigos de viagem & 0,1 & 4,3 & 1,0 & 15,6 \\
\hline IX & Madeira, cortiça e cestaria & 0,0 & 8,5 & 4,2 & 37,7 \\
\hline $\mathrm{X}$ & Produtos de papel e papelão & 2,1 & 26,2 & 3,4 & 20,8 \\
\hline $\mathrm{XI}$ & Têxteis & 1,4 & 13,0 & 2,1 & 24,7 \\
\hline XII & Calçados, chapéus e similares & 0,0 & 3,6 & 7,5 & 66,6 \\
\hline XIII & Pedras, cerâmicas e vidros & 0,7 & 23,2 & 2,0 & 35,4 \\
\hline $\mathrm{XIV}$ & Artigos de joalheria & 0,2 & 12,0 & 2,3 & 58,9 \\
\hline $\mathrm{XV}$ & Ligas de metal & 4,0 & 20,1 & 11,6 & 28,0 \\
\hline $\mathrm{XVI}$ & Maquinaria, eq. Elétricos & 48,6 & 33,3 & 19,1 & 37,0 \\
\hline XVII & Equipamentos de transporte & 5,0 & 13,8 & 22,6 & 41,0 \\
\hline XVIII & Instrumentos de precisão & 6,1 & 36,0 & 1,3 & 41,6 \\
\hline $\mathrm{XIX}$ & Armas e munições & 0,0 & 9,1 & 0,3 & 38,6 \\
\hline$x X$ & Artigos manufaturados diversos & 0,6 & 21,9 & 1,5 & 32,7 \\
\hline & Total & 100,0 & 22,7 & 100,0 & 25,0 \\
\hline
\end{tabular}

Já do lado das importações, como pode ser visto na tabela 1, existe uma maior concentração setorial, onde apenas dois grupos representam 68\% do total, sendo eles Químicos 19,4\% e Máquinas e 
Id on Line Revista Multidisciplinar e de Psicoloqia

Id on Line Revista Multidisciplinar e de Psicologia

Materiais Elétricos 48,6\%, com ainda outros quatro grupos setoriais representando outros $22 \%$, o que leva a $90 \%$ do total em apenas seis grupos.

Vendo a estrutura de comércio entre os dois países, é possível perceber que casos de dumping ou políticas antidumping não justificadas podem ter efeitos muito nocivos às relações comerciais entre esses dois países que podem ser considerados grandes parceiros comerciais.

Como foi visto anteriormente, os casos de dumping que envolve o comércio internacional brasileiro somam 87 casos com medidas aplicadas e em vigor, sendo destes, 31 referentes ao comércio com a China, configurando-se assim como o parceiro comercial com mais penalidades recebidas, mas o EUA também aparece nessa relação com significativo número de medidas, sendo este país o segundo com maior número de medidas aplicadas e em vigor, somando um total de 10 processos.

Para avaliar o impacto dos casos de dumping nas relações comerciais entre Brasil e EUA, veremos alguns casos e discutiremos à luz da teoria qual o efeito reproduzido por tais casos. Em primeiro lugar, é importante destacar que no caso em que o dumping é descoberto e o processo é iniciado, por vezes o país tem direito de aplicar medidas provisórias que lhe permitem aplicar penalidades mesmo antes do julgamento do caso. Ainda vale salientar que as medidas antidumping, tanto provisórias quanto efetivas resultante de um processo, causam distorções nas relações comercias entre esses países.

Para avaliar como isso se verifica empiricamente vamos estudar o caso da Resina de Polipropileno (processos 3902.10.20 e 3902.30.00) que terá medidas antidumping em vigor até 2015. Este caso foi considerado dumping devido ao fato dos preços praticados estarem abaixo do preço normal. Este fato não vinha sendo notado, pois os EUA conduziam o cálculo do preço normal por uma metodologia que favorecia o dumping, sendo nestes processos reavaliado o procedimento para tal cálculo o que possibilitou a constatação da prática do dumping.

O primeiro fato importante desse caso é que esse material é de grande uso industrial e que serve de matéria prima para um grande número de produtos, como é o caso de Tampas flip-top e com dobradiças integradas, peças de parede espessa, fundo de carpete, eletrodomésticos, sacarias, big bags, embalagens para alimentos e produtos têxteis, fitas adesivas, filmes para linhas de conversão, cerdas para vassouras e escovas e etc., mostrando-se assim um produto relevante para nossa análise.

Em segundo lugar, é importante destacar que a penalidade aplicada nestes processos impôs $10,6 \%$ como direito antidumping definitivo, isso encarece o produto industrial brasileiroe causa um desvio do comércio desse produto em relação ao Brasil, pois de acordo com o processo em questão, houve uma substituição do produto por parte dos importadores brasileiros, que buscaram tal produto em países como África do Sul, Coreia do Sul e Índia, obrigando os EUA a buscar novos mercados. Esse fato pode mitigar o desenvolvimento e a manutenção das relações comerciais entre esses dois 
Id on Line Revista Multidisciplinar e de Psicoloqia

Id on Line Revista Multidisciplinar e de Psicologia

Países, pois esse tipo de medida, corretiva, pode ser interpretado como uma medida protecionista e causar grande mal estar nessa relação bilateral.

Por fim, podemos notar que apesar de Brasil e EUA serem grandes parceiros comerciais, a relação entre eles também é conflituosa, principalmente por existirem práticas desleais de comércio e penalidades protecionistas por parte do país prejudicado, o que impossibilita um maior grau de liberdade comercial que deve ser sempre o objetivo dos países. Outro importante fato é que é possível uma verificação e uma aplicabilidade das teorias sobre o dumping e as medidas antidumping nas relações comerciais entre o Brasil e os EUA, mostrando assim a importância do bom conhecimento dessas teorias.

\section{Considerações Finais}

Podemos perceber que a teoria do dumping está sendo bastante discutida atualmente pelos pensadores de comércio internacional, esses tentam uma melhor caracterização do que pode ser considerado dumping, de como os países se utilizam do dumping para aferir maiores ganhos econômicos e como essa prática pode ser punida com direitos antidumping, os quais podem causar danos, tanto ao comércio quanto ao dinamismo econômico dos países envolvidos no processo e até mesmo a terceiros.

Foi possível perceber que as teorias a respeito do dumping tem boa aplicabilidade nos casos das relações comercias brasileiras. Sendo o foco o estudo das relações bilaterais entre Brasil e China e Brasil e EUA. No caso da China podemos perceber que a relação com esse país é fortemente conflituosa, sendo que dos 87 casos de direito antidumping aplicados pelo Brasil este país responde sozinho por 31 casos. Ainda em se tratando da China verificou-se uma boa aplicabilidade das definições de dumping e razoável aplicação das consequências causadas pela aplicação das medidas antidumping.

Já no que diz respeito aos EUA consegue-se perceber que este país tem uma relação comercial pouco conflituosa, tendo apenas 10 casos de dumping registrados com penalidades vigentes, mas que ainda assim pode ser considerado um número significativo, pois dá a este país a segunda colocação em termos de países com mais casos de dumping com processos finalizados e com medidas em vigor. Ainda foi possível perceber que ao analisar os casos de dumping, a teoria do dumping e das medidas antidumping tem sido uma importante ferramenta para a percepção de quais os impactos desses casos sobre o comércio entre esses dois países. 
Id on Line Revista Multidisciplinar e de Psicoloqia

Id on Line Revista Multidisciplinar e de Psicologia

Assim, é possível indicar que a teoria sobre o dumping, bem como a análise dos efeitos dessa prática através do antidumping, podem ser verificadas nas relações comerciais entre as nações, mostrando assim que existem evidências empíricas desse instrumental teórico.

\section{Referências}

ARAUJO Jr., J.T., MACARIO, C., STEINFATT, K. Antidumping in the Americas. Journal of World Trade, v.35, n.4, p. 555-574, 2001.

BARBOSA, A. F.; MENDES, R. C.. As relações econômicas entre Brasil e China: uma prceria difícil. FES Briefing Paper, jan. 2006.

CASTILHO, M. R. O impacto das medidas antidumping aplicadas pelos EUA sobre as exportações brasileiras. In: XXXIV Encontro Nacional de Economia, 2006, Salvador - BA. Anais.

HIDALGO, A. B., Notas de Aula de economia internacional (disciplina economia internacional), PIMES-UFPE, Recife, 2013.

MINISTÉRIO DO DESENVOLVIMENTO, INDÚSTRIA E COMÉRCIO EXTERIOR - MDIC. Medidas Aplicadas em Vigor. $\quad$ Disponível em: http://www.desenvolvimento.gov.br/sitio/interna/interna.php?area=5\&menu=234>. Acesso em: 25 de maio 2013.

MINISTÉRIO DO DESENVOLVIMENTO, INDÚSTRIA E COMÉRCIO EXTERIOR - MDIC. Relatório do DECOM. $\mathrm{N}^{\circ}$ 11/2009. Disponível em: < http://www.desenvolvimento.gov.br/arquivos/dwnl_1275422571.PDF>. Acesso em: 25 de maior 2013.

OLIVEIRA, G. A. S. Determinantes domésticos do antidumping no Brasil - proteção, concorrência e desempenho econômico: uma análise com variável binária e dados em painel. In: XL Encontro Nacional de Economia, 2012, Porto de Galinhas - PE. Anais.

PIRES, M.C.;SOUZA, L.E.S. Brasil e China na Globalização. Série Economia de Bolso, São Paulo, LCTE Editora, 2008.

VASCONCELOS, C. R. F.; FIRME, V. A. Efetividade do Instrumento Antidumping no Brasil entre 1990 e 2007. Economia 12 (2011): 165-184.

VASCONCELOS, C. R. F.; VASCONCELOS, S. P. Medidas "antidumping" e resultados colusivos: o caso do PEBDL na economia brasileira. Nova econ. [online]. 2005, vol.15, n.3, pp. 117-141. ISSN 0103-6351.

VILLELA, Eduardo V. M. As relações comerciais entre Brasil e China e as possibilidades de crescimento e diversificação das exportações de produtos brasileiros ao mercado consumidor chinês. Disponível em <http://www.pucsp.br/geap/artigos/art4.PDF>, em 26 de maio de 2013. 


\section{Como citar este artigo (Formato ABNT):}

SOUSA NETO, E.F.G.; NASCIMENTO. V.L.; QUEVEDO, A.P.F. Evidências Empíricas de Prática de Dumping no Comércio entre Brasil x China e Brasil x EUA. Id on Line Revista Multidisciplinar e de Psicologia, Julho de 2016, vol.10, n.30, Supl 3, p. 205-216 . ISSN 1981-1179.

Recebido: $16 / 05 / 2016$

Aceito: $24 / 05 / 2016$ 